\title{
ELECTRICAL AND FT-IR MEASUREMENTS OF UNDOPED N- TYPE INP MATERIALS GROWN FROM VARIOUS STOICHIOMETRIC MELTS
}

\author{
X.D.Chen', N.F.Sun ${ }^{1}$, T.N.Sun ${ }^{1, *}$, S.L.Liu', G.Y.Yang', \\ Y.W.Zhao ${ }^{1,2}$, X.L.Xu' ${ }^{2}$ C.D.Beling ${ }^{2}$, S.Fung ${ }^{2}$ \\ Hebei Semiconductor Research Institute, P. O. Box 179-40, Shijiazhuang, Hebei, P.R.China' \\ Department of Physics, The University of Hong Kong, P.R.China ${ }^{2}$ \\ Email:tnsun@public.sj.he.cn*
}

\begin{abstract}
P-rich, In-rich and Stoichiometric undoped InP melts have been synthesed by phosphorus in-situ injection method. InP crystal ingots have been grown from these melts by Liquid Encapsulated Czochralski (LEC). Samples from these ingots grown from various Stoichiometric melts have been characterized by Hall Effect and Fourier Transform Infrared (FT-IR) spectroscopy measurements respectively. The Hall Effect measurement results indicate that the net carrier concentration of P-inch undoped InP is higher than that of In-rich and Stoichiometric undoped InP materials. FT-IR spectroscopy measurements reveal that there are intensive absorption peaks which have been proved to be hydrogen related indium vacancy complex $\mathrm{V}_{\mathrm{In}} \mathrm{H}_{4}$. By comparing FT-IR spectra, it is found that Prich InP material has the most intensive absorption peak of $\mathrm{V}_{11} \mathrm{H}_{4}$, while In-rich InP material has the weakest absorption peak.
\end{abstract}

\section{Introduction}

InP is the basic material for long wavelength optoelectronic devices, and its importance for high frequency devices (HEMTs, HBTs) increases continuously. There is a growing interest in high purity InP crystal for the preparation of undoped semi-insulating wafers by annealing.

High purity InP crystal materials have been produced by the phosphorus in-situ injection synthesis and growth process. ${ }^{[1,2,3]}$ The in-situ process has several advantages over the two-step process of compounding and growing in separate furnaces. Especially, various Stoichiometric $\operatorname{In} P$ melts can be achieved by phosphorus in-situ injection method directly, and followed by LEC crystal growth of InP without exposure to potential contamination outside the furnace environment.

The authors have investigated the thermal field and velocity of phosphorus injection during synthesis process in order to achieve controlling of P-rich, Stoichiometric or In-rich InP melts. After synthesis process, InP crystal ingots with various Stoichiometric characteristics have been grown by LEC method from various Stoichiometric melts. The raw materials $\left(6 \mathrm{~N}\right.$ In, $\left.6 \mathrm{~N} \mathrm{P}, \mathrm{B}_{2} \mathrm{O}_{3}\right)$ for $\operatorname{InP}$ synthesis and growth are of the same batch from the same suppliers. Their background impurity contents are of the same level. So the characteristic difference in these crystal materials should be attributed to change of melt Stoichiometry.

\section{Experiment}

A series of experiments was performed to investigate characteristics of InP crystals grown from various Stoichiometric melts. The experimental chamber is shown in Figl.

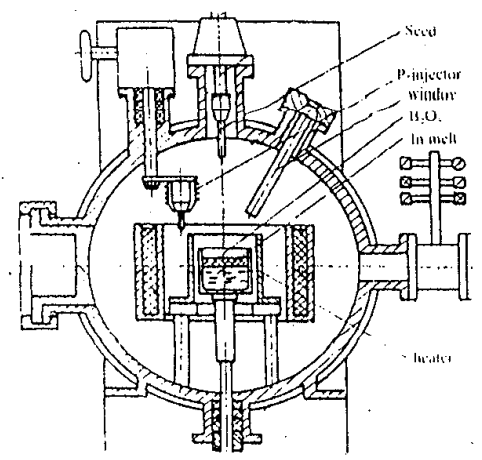


Fig 1. Schematic diagram of synthesis and growth Chamber

In the chamber, injector motion and seed motion are controlled independently. During the first phase the injector is lowered into the melt while the seed remains in a high position. For the next phase (the initiation of growth), the injector is raised and moved aside, the seed is lowered and inserted into melts.

In experimental process, thermal field and velocity of phosphorus injection are all key factors to P-rich synthesis and crystal growth. By investigating these factors, the authors achieved controlling of Stoichiometry of InP melts and growing crystal ingots from various Stoichiometric melts. The conditions and results of synthesis and growth are shown in Table 1.

Table 1. Synthesis conditions and growth results

\begin{tabular}{|c|c|l|}
\hline No. & {$[$ In $] /[\mathrm{P}](\mathrm{mol})$} & \multicolumn{1}{|c|}{ Result } \\
\hline $\mathrm{M}-\mathrm{B}-27$ & 0.92 & P-rich \\
\hline $\mathrm{M}-\mathrm{B}-25$ & $\sim 1$ & Stoichiometric \\
\hline $\mathrm{M}-\mathrm{B}-24$ & 1.04 & In-rich \\
\hline $\mathrm{P}_{1}-\mathrm{B}-87$ & 0.95 & P-rich \\
\hline $\mathrm{P}_{1}-\mathrm{B}-54$ & $\sim 1$ & Stoichiometric \\
\hline $\mathrm{P}_{1}-\mathrm{B}-51$ & 1.06 & In-rich \\
\hline $\mathrm{P}_{2}-\mathrm{B}-21$ & 0.90 & P-rich \\
\hline $\mathrm{P}_{2}-\mathrm{B}-03$ & $\sim 1$ & Stoichiometric \\
\hline $\mathrm{P}_{2}-\mathrm{B}-10$ & 1.08 & In-rich \\
\hline
\end{tabular}

Cross sections of crystal ingots grown from In-rich and P-rich melts are shown as Fig 2.

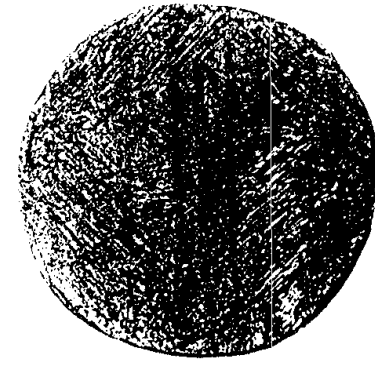

$\mid: 1-$ ricls

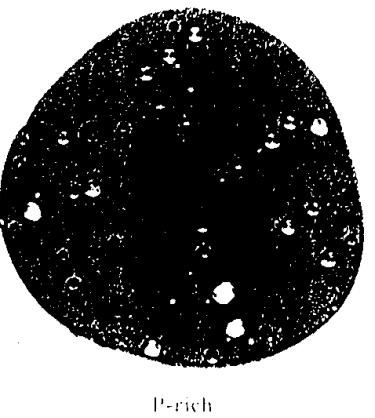

Fig 2. Photos of In-rich and P-rich wafers

From these photos, one can see that there are some pores caused by excess phosphorus in these sample wafers grown from P-rich InP melts.
III. Results and Discussion

Samples from these ingots are characterized by Hall Effect and FT-IR spectroscopy measurements respectively. The Hall Effect results indicate that the net carrier concentration of P-rich undoped InP materials is higher than that of In-rich and Stoichiometric materials, the data are given in Table 2 .

Table 2. Hall Effect measurement results

\begin{tabular}{|c|l|c|c|}
\hline No. & Stoichiometry & $\begin{array}{c}\left(\mathrm{N}_{\mathrm{D}^{-}}-\mathrm{N}_{\mathrm{A}}\right) \\
\times 10^{15} \mathrm{~cm}^{-3}\end{array}$ & $\begin{array}{c}\mu \\
\times 10^{3} \mathrm{~cm}^{2} / \mathrm{Vs}\end{array}$ \\
\hline M-B-27 & P-rich & 3.51 & 4.15 \\
\hline M-B-25 & Stoichiometric & 2.72 & 4.62 \\
\hline M-B-24 & In-rich & 1.96 & 4.35 \\
\hline$P_{1}-\mathrm{B}-87$ & P-rich & 4.76 & 4.57 \\
\hline$P_{1}-\mathrm{B}-54$ & Stoichiometric & 3.99 & 4.58 \\
\hline$P_{1}-\mathrm{B}-51$ & In-rich & 2.58 & 4.78 \\
\hline $\mathrm{P}_{2}-\mathrm{B}-21$ & P-rich & 4.87 & 4.45 \\
\hline $\mathrm{P}_{2}-\mathrm{B}-03$ & Stoichiometric & 2.41 & 4.67 \\
\hline $\mathrm{P}_{2}-\mathrm{B}-10$ & In-rich & 2.24 & 4.82 \\
\hline
\end{tabular}

FT-IR spectroscopy measurernents reveal that there are intensive absorption peaks of hydrogen related local vibration model (H-LVM, $2316 \mathrm{~cm}^{-1}$ ) in all of spectra (shown in Fig. 3 ).
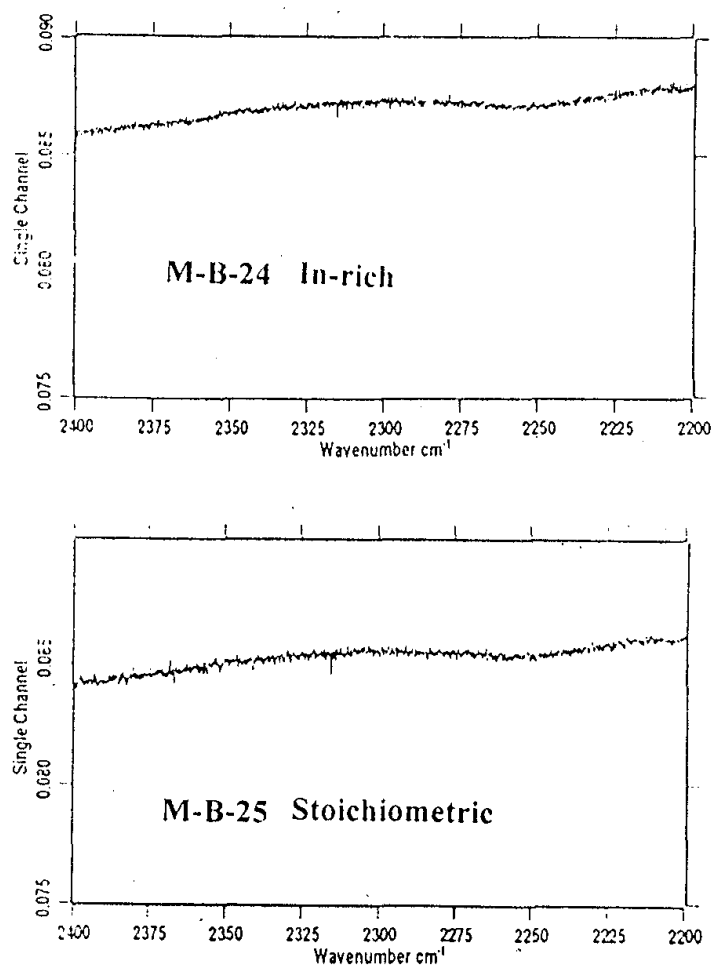


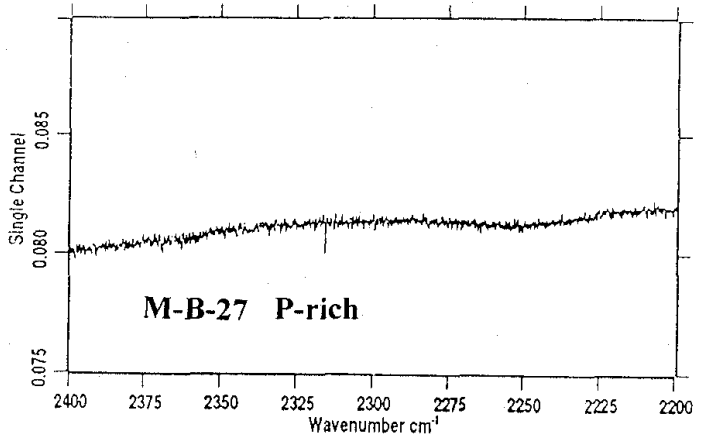

Fig. 3 FT-IR measurement spectra

The intensive absorption peaks indicate that our phosphorus in-situ injection synthesis LEC undoped InP materials have relatively high concentration of hydrogen related complexes. By comparing FT-IR Spectra, it is found that the intensity of H-LVM at $2316 \mathrm{~cm}^{-1}$ is different under three kinds of Stoichiometric cases. P-rich undoped InP material has the most intensive absorption peak, while In-rich material has the weakest one and the Stoichiometric InP is between the two of them.

The hydrogen related complex at $2316 \mathrm{~cm}^{-1}$ has been proved to be hydrogen related indium vacancy complex $\mathrm{V}_{\mathrm{In}} \mathrm{H}_{4}{ }^{[4,5]}$. It has been proved to be acting as shallow donor in $\operatorname{In} \mathrm{P}$ materials by theory calculation. As a special and important complex defect, $\mathrm{V}_{\mathrm{In}} \mathrm{H}_{4}$ is the key factor to the preparation of undoped semi-insulating InP materials by annealing, ${ }^{[6]}$ the concentration of the complex under various Stoichiometric conditions is necessary to be studied.

The indium vacancy formation energy of P-rich $\mathrm{N}$ type InP melts is lower than that of In-rich melt, the concentration of each complex defect to formation energy can be expressed as follows:

$$
[x]=\partial(x) N_{c} \exp (-\Delta \mu / \kappa \mathrm{T})
$$

Where $a(x)$ is the configurational degeneracy of the positions of defects, $\Delta \mu$ is the formation energy and $N_{c}$ is the atom number in unit volume. For P-rich InP melt, lower formation energy of indium vacancy must enhance the concentration of indium vacancy, that is there are more $\mathrm{V}_{\mathrm{In}}{ }^{3-}$ in InP crystal grown from P-rich than In-rich melts. So it is relatively easy to detect indium vacancy defect level in P-rich InP materials ${ }^{[3]}$.

$\mathrm{V}_{\mathrm{In}} \mathrm{H}_{4}$ comes from the reaction of $\mathrm{V}_{\mathrm{In}}{ }^{3-}$ and $\mathrm{H}$. The formation energy of this complex is lower than that of isolated indium vacancy $\mathrm{V}_{\mathrm{In}}{ }^{3-[6]}$, the concentration of $\mathrm{V}_{\mathrm{In}} \mathrm{H}_{4}$ in the form of mass action expression is as follows:

$$
\left[V_{l n} H_{4}\right]=k_{n} \times[H]^{4} \times\left[V_{l n}^{3-}\right] / 4
$$

where [ ] denotes the concentration of complexes, $k_{n}$ is the reaction constant. For the crystal grown from P-rich melts, lower formation energy should cause higher concentration of indium vacancy. According to the mass action law equation (2), higher concentration of indium vacancy must increase the concentration of hydrogen related indium vacancy complex $\mathrm{V}_{\mathrm{In}} \mathrm{H}_{4}$. As $\mathrm{V}_{\mathrm{In}} \mathrm{H}_{4}$ is a shallow donor complex, the excitement of this complex can increase the electron concentration, so higher carrier concentration is expected for P-rich samples. The Hall Effect measurement results, which indicate P-rich crystal samples have higher carrier concentration, are in agreement with FT-IR spectroscopy measurement spectra.

\section{Conclusions}

Considering the grown condition of our undoped phosphorus in-situ injection LEC InP, we can conclude that it is the Stoichiometry condition that causes the InP materials grown from P-rich melts have higher carrier concentration than that of InP materials grown from In-rich melts. The extra donor is hydrogen indium vacancy complex. There have been reports of extra donor in LEC InP. According to our electrical and FT-IR measurements of undoped n-type InP grow from various Stoichiometric melts, we believe that the unidentified donor is most likely $\mathrm{V}_{\mathrm{In}} \mathrm{H}_{4}$, and $\mathrm{V}_{\mathrm{In}} \mathrm{H}_{4}$ is most likely the "missing donor" in InP annealing process. The result of this work, which shows the influence of stoichiometry on the concentration of $\mathrm{V}_{\text {in }} \mathrm{H}_{4}$ is also an evidence that the extra donor in LEC InP is hydrogen related indium vacancy complex $\mathrm{V}_{\mathrm{ln}} \mathrm{H}_{4}$.

\section{Reference}

(1) S. Tong-nien, L. Szu-lin and k. Shu-tseng "Semiinsulating III-V Materials, Evian, 1982, pp. 61-67.

(2) J. Fargers et al. Journal of Crystal Growth, Vol.59, 1982, pp. 665-668.

(3) D. F. Bliss et al. Journal of Electronic Materials, Vol.20, 1991, pp. 967-971.

(4) R. Darwich, B. Pajot, et al. Phys. Rèv. B48, Vol.17, 1993, pp. 776-790.

(5) C. P. Ewels, S. Oberg, B. Pajot and P. R. Briddon, Semicond. Sci. Technol. Vol.11, 1996, pp. 502

(6) Y. W. Zhao, X. D. Chen, et al. Appl. Phys. Lett. 1998, (to be published) 